\title{
SYNTHESIS AND CHARACTERIZATION OF FeNi ALLOYS NANOPARTICULATE
}

\author{
dos Santos, C. M.*; Martins, A. F. N.; Braga, T. P.; Sasaki, J. M. \\ Department of Physics, Federal University of Ceará, Fortaleza, Ceará, Brazil.
}

*cmorillasantos@yahoo.com.br

\begin{abstract}
Superparamagnetic properties of alloys nanoparticulate have been much studied in recent years due applications in medical and biological areas. This due to the possibility of its use in cancer treatment, vector for transport of drug for the cells and applications as catalysts. The development of new synthetic routes economically viable for synthesis of these materials is of fundamental importance. In this work, the formation of FeNi alloy nanoparticles by the proteic sol-gel method was studied as a function of temperature and reduction flow, and its crystalline characteristics studied by X-ray diffraction associated with Rietveld refinement. Initially, reductions were made in $\mathrm{H}_{2}$ atmosphere with flux of $30 \mathrm{~mL} / \mathrm{min}$ at several temperatures $\left(500,600,650\right.$ and $\left.700{ }^{\circ} \mathrm{C}\right)$. Later, the reductions were carried out also in $\mathrm{H}_{2}$ atmosphere, but at a temperature of $500^{\circ} \mathrm{C}$ and distinct flow rates $(25,30,40$ and $50 \mathrm{~mL} / \mathrm{min})$. Pure alloy was obtained for samples reduced at 650 and $700^{\circ} \mathrm{C}$ with a flux of $30 \mathrm{~mL} / \mathrm{min}$. With respect to variation of the reduced flux, pure alloy was obtained for 40 and $50 \mathrm{~mL} / \mathrm{min}$. Rietveld refinement was performed using the GSAS software and interface of EXPGUI, and allowed to determine the microstructural characteristics of the samples. After the crystallographic analysis, we will study magnetic and morphological properties.
\end{abstract}

